\title{
PSYCHOMETRIC SOCIETY MEETING OF THE MEMBERS VIRTUAL MEETING JULY
}

17,2020

Carolyn Anderson, Secretary called the meeting to order at 11:02 CT.

\section{Approval of 2019 Meeting Minutes:}

Carolyn called for the approval of the 2019 Meeting of the Members minutes. A motion was made by Jacqueline Meulman and seconded by Maarten Kampert. Motion carried.

\section{Psychometric Society Treasurer Report:}

Matt Johnson provided a report on the financial standing of the society. Starting equity for 2018 was $\$ 476,138,2019$ was $\$ 533,633$, and 2020 was $\$ 533,002$. Because expenses are always higher during an international IMPS year, the change in equity between 2019 and 2020 was negligible. Disbursements were comparable between 2018 and 2019, with $\$ 355,821$ spent in 2018 and $\$ 378,716$ spent in 2019 . The international meeting and investments in the new website account for the higher expenses in 2019. 2019 was a good year for the investment accounts, with a gain of $\$ 35,384$ dollars. Carolyn called for a motion to approve the Treasurer Report. David Kaplan made a motion to approve the Treasurer Report. Steven Culpepper seconded the motion. Motion carried.

\section{Psychometrika Editor Report:}

Matthias von Davier, Executive Editor, discussed the journal. He thanked the associate editors and editorial board. Matthias discussed the geographic breakdown of submissions. He reviewed the number of days from submission to first decision, usage, and impact factor. Currently the average is 77 days from submission to first acceptance. Matthias discussed the number of submissions as of July $12^{\text {th }}$, with 134 submissions for the first half of 2020.70 submissions are either in revision, under review, conditionally accepted, or accepted.

Eddie Ip discussed three special issues for the ARCS section of the journal. One ARCS special issue is Network Psychometrics in Action with guest editors Maarten Marsman and Mijke Rhemtulla. The second is forecasting with Intensive Longitudinal Data, with guest editors Peter Halpin, Siwei Liu, and Kathleen Gates. The third is on applying psychometric methods to assessing patient-reported outcomes: Lessons learned from the Patient- Reported Outcomes Measurement Information System (PROMIS ${ }^{\circledR}$ ) initiative with guest editors Bryce Reeve and Ron Hayes.

A question was raised about any efforts underway to increase diversity and inclusion of authors and editors. Matthias discussed the work of the Editorial Council in this area. Carolyn discussed the diversity and inclusion statement the Board of Trustees is developing and the need to increase diversity within the society. She asked members to submit suggestions to facilitate these efforts to herself, or any member of the Board of Trustees.

\section{Approval of New Members:}

Carolyn shared the list of new members and called for a vote to approve these individuals as members. Dave Thissen made a motion to approve the members as presented. Anne Thissen-Roe seconded the motion. Motion carried. 


\section{Election Results:}

Carolyn shared the new members of the Board of Trustees. President Elect is Jeffrey Douglas. Elected Board members are Jimmy de la Torre, Minjeong Jeon, and Duanli Yan. Editorial Council held its election and David Kaplan was elected Chair.

\section{Upcoming Vote on Psychometric Society Issues:}

Carolyn discussed the upcoming election for Treasurer Elect. Candidates are Qiwei (Britt) He and Ed Merkle. She reviewed the second issue on the ballot, which is to extend terms of the President, President Elect and Past President by one year since the COVID-19 pandemic forced cancellation of the in-person IMPS meeting. She discussed the third issue, which is extending the terms of the elected Board of Trustees members by one year. Carolyn reviewed the changes to the Bylaws that are also included on the ballot. Voting will open after the Meeting of the Members and will close August 17, 2020.

\section{IMPS 2020:}

Dan Bolt discussed the move to a virtual conference due to the COVID-19 pandemic. ExOrdo was the company used for abstract submission. At the time the conference needed to move virtually, ExOrdo was also building a virtual meeting platform that tied to the abstract platform. This was the platform used for the conference. There were 230 abstracts submitted. The total number of registrants were 378. 130 members, 61 non-members, 181 students, and 6 retired members registered. 52 individuals registered for the short course. This year short course registration included access to the entire IMPS conference. Dan encouraged everyone to fill out the evaluation when it distributes.

\section{IMPS 2021:}

Dan discussed the contracts with the University of Maryland Stamp Union, The Hotel, and the Spy Museum. These contracts were in place for the 2020 meeting and deposits had been made. All deposits will be applied to the 2021 meeting. Meeting dates will be July 18-23, 2021. Several speakers who did not present at the 2020 Virtual IMPS will be on the schedule for 2021. Carolyn thanked Dan for his work this year and for the work he will put in for 2021. Dan thanked Carolyn and Ed Merkle for all their support for the virtual conference. He thanked everyone who worked on the virtual conference.

\section{IMPS 2022:}

Irini Moustaki discussed the plans for Bologna, Italy in 2022.

\section{Conference Proceedings:}

Carolyn provided the update on the proceedings. The 2019 Proceedings are now available, with 28 chapters and topics that include IRT, factor analysis, hierarchical models, computerized adaptive testing, and other topics. Editors for the 2019 Proceedings are Marie Wiberg, Dylan Molenaar, Jorge González, Ulf Böckenholt, and Jee-Seon Kim. The editorial team will remain the same for 2020. 2020 Proceedings timeline will be August 1, 2020 Authors to confirm submission with title. October 1, 2020 the first draft to be submitted. November 12, 2020 Reviews returned to authors. January 4, 2021 is the final paper deadline.

\section{Website:}

Ed Merkle discussed the new website built by Digital Deployment. The website launched in March. He discussed the easier navigation of the new website and the ease to add content. He reminded everyone to stay online after the meeting for the virtual group photo

\section{New Society Logo:}

Carolyn revealed the new logo. Dan thanked David Torres Ibarra who created the new logo. David was one of the co-hosts in Santiago for IMPS 2019. 


\section{New Business:}

Carolyn called for new business. Hearing none, she called for the group photo.

Motion to adjourn: Terry Ackermann made a motion to adjourn. David Kaplan seconded the motion. Meeting adjourned at 11:48 a.m. CT.

Publisher's Note Springer Nature remains neutral with regard to jurisdictional claims in published maps and institutional affiliations. 